\title{
A Pesquisa em Física no Curso de \\ Licenciatura Interdisciplinar em Educação do \\ Campo
}

\section{The Physics Research in the Interdisciplinary Degree in Countryside Education}

\author{
Angelo Donizete Ribeiro (angelodonizeteribeiro@yahoo.com.br) \\ Universidade Federal da Fronteira Sul, UFFS, Laranjeiras do Sul, PR, Brasil \\ Vivian Machado de Menezes (demenezes.vivian@gmail.com) \\ Universidade Federal da Fronteira Sul, UFFS, Laranjeiras do Sul, PR, Brasil
}

Resumo: Este trabalho teve como objetivo analisar os impactos dos projetos de pesquisa na aprendizagem de Física dos estudantes do curso de Licenciatura Interdisciplinar em Educação do Campo: Ciências Naturais, Matemática e Ciências Agrárias, da Universidade Federal da Fronteira Sul, campus Laranjeiras do Sul. Primeiramente, foi realizado um levantamento bibliográfico acerca dos projetos de pesquisa, contextualizando com a disciplina/ensino de Física. Posteriormente, foi realizada uma entrevista estruturada com os estudantes que participaram dos projetos de pesquisa vinculados ao curso de Educação do Campo, com o intuito de saber a opinião dos mesmos acerca da contribuição destes projetos no processo de aprendizagem de Física e também na sua formação profissional. De acordo com a pesquisa exploratória realizada, percebe-se que os projetos contribuem de forma positiva para os acadêmicos, tanto no viés da aprendizagem de Física quanto na formação profissional proposta pelo curso, pois eles representam uma maneira de associar a teoria à prática, possibilitando novas formas de ensino e aprendizado, por meio das atividades desenvolvidas.

Palavras-chave: Pesquisa Universitária; Educação do Campo; Ensino de Física.

Abstract: This work has the objective of analyzing the impact of research projects on the learning of students of the Interdisciplinary Degree in Countryside Education: Natural Sciences, Mathematics, and Agrarian Sciences, of the Federal University of Fronteira Sul, campus Laranjeiras do Sul. Firstly, a bibliographical survey was carried out about the research projects, contextualizing with the discipline/teaching of Physics. Posteriorly, a structured interview was carried out with the students who participate in the research projects linked to the Countryside Education course, in order to know about the opinion on the contribution of these projects to their learning and also to vocational training. According to the exploratory research carried out, it can be seen that the projects contribute positively to the students, both in terms of Physics learning and in the professional formation proposed by the course, as they represent a way of associating theory with practice, enabling new forms of teaching and learning, through the activities developed.

Keywords: University Research; Countryside Education; Physics Teaching. 


\section{INTRODUÇÃO}

O curso de graduação em Licenciatura Interdisciplinar em Educação do Campo: Ciências Naturais, Matemática e Ciências Agrárias - LEDOC-CNMA, ofertado na Universidade Federal da Fronteira Sul - UFFS, campus Laranjeiras do Sul - PR, tem por objetivo a formação de profissionais na área da Educação, especialmente na Educação do Campo. O curso de LEDOC-CNMA, além de procurar formar profissionais competentes, que sejam capazes de compreender as especificidades dos povos do campo, também trabalha com disciplinas que abrangem uma área de conhecimento ampla, conhecida como Ciências da Natureza e da Matemática, da qual fazem parte disciplinas específicas trabalhadas na grade curricular do curso: Matemática, Química, Física e Biologia, além das Ciências Agrárias.

As áreas de conhecimento das Ciências da Natureza e da Matemática têm como característica possibilitar o entendimento dos fenômenos de transformação da natureza e suas relações, especificando os desdobramentos de tais fenômenos. De acordo com a Base Nacional Comum Curricular do Ensino Médio - BNCC (BRASIL, 2017) é competência específica das Ciências da Natureza analisar situações-problema e avaliar aplicações do conhecimento científico e tecnológico e suas implicações no mundo, utilizando procedimentos e linguagens próprios das Ciências da Natureza, para propor soluções que considerem demandas locais, regionais e/ou globais, e comunicar suas descobertas e conclusões a públicos variados, em diversos contextos e por meio de diferentes mídias e tecnologias digitais de informação e comunicação. Assim, observase a importância da área das Ciências da Natureza e da Matemática, considerando a crescente valorização do conhecimento e da capacidade de inovar, pois demanda cidadãos capazes de aprender continuamente. Como já citado neste trabalho, entre as disciplinas que os estudantes do curso de Licenciatura Interdisciplinar em Educação do Campo estudam, está a Física, que é foco deste trabalho.

Assim, o presente trabalho visa investigar a relação entre os projetos de pesquisa desenvolvidos por estudantes do curso LEDOC-CNMA com o desempenho dos mesmos nas disciplinas de Física. De modo geral, tem o objetivo de demonstrar os aspectos positivos que os estudantes conseguem lapidar nos projetos e aplicar esses conhecimentos no desenvolvimento das disciplinas, investigando questões relacionados aos seus pontos positivos e negativos e as contribuições dos mesmos para a formação 
profissional do curso em questão. Para tanto, o artigo está estruturado em duas partes, sendo na primeira realizado um levantamento teórico bibliográfico pautado em pesquisas de materiais diversos, como artigos, teses, monografias e livros. São abordados os temas Pesquisa Universitária e o Ensino de Física, elencando aspectos históricos e atuais pertinentes. Na segunda parte apresentam-se os resultados, coletados a partir de entrevistas estruturadas, constituídas por perguntas abertas, o que possibilitou ao entrevistado uma maior liberdade em suas respostas. Para a realização destas entrevistas, foram selecionados dezesseis acadêmicos do curso de Educação do Campo, cujo critério de escolha foi sua participação em projetos de pesquisa em Física vinculados ao curso de LEDOC-CNMA da Universidade Federal da Fronteira Sul de Laranjeiras do Sul, até novembro de 2017. A identidade dos entrevistados foi preservada, optando-se pela utilização de nomes fictícios, e a discussão acerca das respostas obtidas foi pautada na bibliografia disponível. Os resultados apontam para um reconhecimento sobre a contribuição dos projetos na adoção de novas metodologias e estratégias didáticas para o ensino da Física.

\section{PESQUISA UNIVERSITÁRIA: SÍNTESE HISTÓRICA E DEFINIÇÕES}

Os registros históricos da pesquisa universitária no Brasil datam do final do século XIX, quando esta começa a dar seus primeiros passos no ensino superior. Estudos de Schwartzman (1982) registram que os resquícios iniciais da pesquisa universitária no Brasil aparecem na Escola de Medicina da Bahia, onde Nina Rodrigues esteve à frente de uma série de atividades e experimentos em Medicina Legal, entre 1891 e 1905.

Por meio do Decreto $\mathrm{n}^{\mathrm{o}}$ 19.851, de abril de 1931, instituído por Francisco Campos, o modelo de universidade deliberativa pela "investigação científica em quaisquer domínios dos conhecimentos humanos" é introduzido no Brasil. Porém, apesar deste decreto, o ensino enciclopédico ainda perdurou por muito tempo no ensino superior do país. Silva (2014) destaca que o cenário brasileiro para o progresso científico não era favorável, pois a economia era basicamente agrícola, alto índice de analfabetismo, forte concentração de renda e limitado acesso da população ao Ensino Superior.

No que se refere a Ensino Superior com relevância em ensino pautado na pesquisa 
e produção científica, a Universidade de São Paulo - USP, fundada em 1934, foi um modelo de universidade instituída com base em modelos no desenvolvimento em pesquisa em tempo integral, sendo influenciada pela Inglaterra e pelos Estados Unidos. Outra universidade que se destacou nessa linha de pensamento foi a Universidade de Brasília - UnB, fundada em 21 de abril de 1962. Esta última surgiu alinhada a correntes progressistas, com um modelo de Educação Superior inovador, proporcionando, além do desenvolvimento necessário à região da nova sede política do Brasil (Brasília havia sido criada por Juscelino Kubitschek em 1960), importantes avanços de ordem econômica, científica, tecnológica e política na sociedade nacional, dando início, assim, a um novo jeito de se pensar e fazer Educação Superior (SILVA, 2014).

A Lei 5.540/68 foi responsável por importantes e drásticas mudanças no Ensino Superior, pois propôs a criação de departamentos, substituição do regime de cátedras, ensino como atividade indissociável da pesquisa e exigência da pós-graduação para manutenção da carreira docente.

A partir de então, a mudança no Ensino Superior passou a contar com o auxílio de organizações voltadas ao financiamento e desenvolvimento da pesquisa no Ensino Superior. O modelo de Ensino Superior pautado na pesquisa científica avançou e teve, na Constituição Federal de 1988, em seu artigo 207, a definição de conceito como "universidade por meio do princípio de indissociabilidade do ensino, pesquisa e extensão"(BRASIL, 1988).

Mais recentemente, nos anos 2000, o processo de disseminação do Ensino Superior levou à criação de políticas públicas, como a Lei $n^{0}$ 10973/2004, que incentivou a inovação e a pesquisa científica e tecnológica no ambiente produtivo, e a Lei $\mathrm{n}^{\mathrm{o}} 11079 / 2004$, que instituiu normas gerais para a licitação e contratação de parcerias público-privadas. Estas leis estabelecem e fortalecem parcerias do Estado com empresas privadas em diferentes áreas de atuação, permitindo o desenvolvimento da pesquisa ao gerar substanciais investimentos financeiros com possibilidade de gratificação aos pesquisadores.

Araújo e Salgues (2008) discutem sobre a pesquisa interdisciplinar no contexto universitário que surge "como sendo uma possibilidade de superação da dicotomia ensino/pesquisa, um passo a mais no sentido da interdisciplinaridade". Eles comentam que, para os conhecimentos integrados e interdisciplinares serem produzidos, não se 
agrupa saberes em forma de disciplinas, mas se reunem as atividades dos docentes pela prática do trabalho cooperativo, juntos em torno de um mesmo problema de pesquisa.

O desenvolvimento de projetos de pesquisa durante a graduação é de grande importância e tem por objetivo contribuir com a evolução dos saberes humanos em todos os setores, sendo estes projetos, sistematicamente planejados e executados através de rigorosos critérios de processamento das informações. Os trabalhos de graduação devem produzir ciência, ou dela derivar (ANDRADE, 2003).

Em se tratando de realidade vivenciada, podemos discutir a respeito da função da pesquisa universitária na Universidade Federal da Fronteira Sul - UFFS. A referida Universidade, fundada em 2009 e inaugurada em 2010, nasceu da força e luta de movimentos sociais e hoje conta com seis campi: Chapecó (SC) - sede da instituição, Realeza (PR), Laranjeiras do Sul (PR), Cerro Largo, Erechim (RS) e Passo Fundo (RS) - que oferece o primeiro curso de Medicina do Brasil instituído por meio do programa de expansão das escolas médicas do Governo Federal. O livro Construindo agendas e definindo rumos: I Conferência de Ensino, Pesquisa e Extensão da UFFS (COEPE), destaca a função da pesquisa universitária na UFFS:

Orientada pelos princípios éticos e epistemológicos colocados acima, a Pesquisa na UFFS visa aos seguintes objetivos:

1. Respeitar os princípios éticos e epistemológicos que orientam as atividades-fim da UFFS;

2. Observar os princípios da ética científica na definição das finalidades da Pesquisa, no uso das metodologias, na divulgação dos resultados e na utilização das verbas públicas;

3. Promover o avanço do conhecimento em todas as suas áreas;

4. Contribuir para que a UFFS se constitua em um centro de referência em tecnologias e inovação social, comprometida com o desenvolvimento social, cultural e econômico, de forma sustentável e solidária;

5. Promover o acesso aos conhecimentos e tecnologias, por meio da integração com o Ensino e a Extensão e do apoio à divulgação dos resultados das pesquisas;

6. Contribuir para a formação acadêmica;

7. Subsidiar a elaboração de políticas públicas que atendam às necessidades oriundas dos processos de desenvolvimento;

8. Criar espaços plurais, fomentando o diálogo e o debate entre diferentes posições teóricas, olhares e perspectivas;

9. Fomentar a interlocução e o debate entre os pesquisadores dos diferentes campi e instituições, visando a consolidação dos Grupos e das Linhas de Pesquisa;

10. Delinear campos de problematização que permitam a investigação sob a perspectiva resultante da interlocução de diferentes áreas do conhecimento, buscando construir respostas inovadoras;

11. Potencializar a formação de pesquisadores por meio de parcerias, intercâmbios e acordos de cooperação com outras instituições nacionais e internacionais. (TREVISOL; CORDEIRO; HASS, 2011, p. 62). 
A Política de Pesquisa da UFFS (UFFS 2011) define que a extensão:

\begin{abstract}
Parte dos problemas da região da Fronteira Sul se deve à histórica ausência de políticas públicas orientadas para o desenvolvimento e a superação das desigualdades socioeconômicas. A superação desses problemas requer conciliar conhecimento da realidade com a preservação ambiental, a melhoria da qualidade de vida de todos e a produção e inovação científica, tecnológica e cultural. Nesse contexto, a UFFS é desafiada a organizar as atividades de Pesquisa de forma a dialogar com a sociedade, reafirmando seu compromisso com a construção de uma instituição pública, popular e de qualidade e desempenhando seu papel de locus de problematização da realidade social (UFFS, 2011, p. 43).
\end{abstract}

Vale ressaltar que, de acordo com Souza (2017), a pesquisa na UFFS não caminha desvinculada dos parâmetros nacionais para a atividade. As ações extensionistas da universidade seguem normas de organização e operacionalização conforme orientações repassadas pelo Plano Nacional de Extensão do Sistema de Informações e de Dados da Extensão (SIEXBRASIL), estipuladas pelo Fórum de Pró-Reitores de Extensão das Instituições Públicas de Educação Superior Brasileiras (FORPROEX) para poderem ser aplicadas no território nacional, estadual e regional.

\title{
3. A DISCIPLINA DE FÍSICA EM CONTEXTO
}

Vários estudos revelam o progresso lento de avanços obtidos na área da Física, relativos aos métodos e objetos de estudo, revelando a forte influência internacional nesse processo. Estudos realizados por Nardi (2005) mostram que entre as décadas de 40 e 50 foram observadas várias ações que facilitaram a construção dos primeiros grupos de pesquisa de Ensino de Física no Brasil, citando a Universidade Federal do Rio Grande do Sul - UFRGS e a Universidade Federal de São Paulo - UNIFESP.

De acordo com vários estudos, há uma prática de memorização de fórmulas e desenvolvimento de modelos matemáticos de ensino, que não priorizam a aproximação da Física com a realidade do aluno, o que seria possível, por exemplo, através de estudos sobre fenômenos naturais. Estudos de Pedrisa (2001) apontam que o ensino das ciências físicas e naturais no país está fortemente influenciado pela ausência da prática experimental, dependência excessiva do livro didático, método apenas expositivo, reduzido número de aulas, currículo desatualizado e descontextualizado e profissionalização insuficiente do professor (DIOGO; GOBARA, 2007).

Percebe-se, assim, a grande necessidade de um investimento inicial na formação dos profissionais da Educação, que, munidos de conhecimentos teóricos e práticos 
possibilitados pelos projetos de pesquisa universitária, possam atuar na mudança de paradigmas em relação ao Ensino de Física. É nesse contexto que a formação profissional tem adotado metodologias diferenciadas para capacitar cada vez mais estes profissionais da Educação, para que sua atuação na área de ensino seja mais voltada a abordagens de conteúdos relacionandos com a realidade do aluno, utilizando o meio em que vivem como subsídio para construção do conhecimento, possibilitando assim, um ensino mais significativo.

Os projetos de pesquisa acerca das disciplinas exatas, especificamente da disciplina de Física, visam a integração entre a teoria e a prática na construção de um conhecimento mais significativo, que objetive ao discente vivenciar os fenômenos estudados e poder agir sobre os mesmos, de forma a confrontar as informações obtidas, atribuindo-lhes características sociais, relacionando-os a situações reais. Além disso, visam a formação de profissionais capazes de planejar e organizar uma metodologia de ensino voltada à produção de conhecimentos por meio da pesquisa, que, conforme Demo (1999), significa que o educando seja capaz de alimentar-se de diversas fontes para aprimorar sua base teórica, não se permitindo ser um mero reprodutor de conteúdos de livros ou de fragmentos retirados aleatoriamente da internet ou de obras de outrem.

\begin{abstract}
A pesquisa nas universidades não é um mal necessário, não é um bem desnecessário, ela é o germe da evolução, ela é um bem impreterível e profundamente necessário... A pesquisa nem sempre melhora a didática dos professores (qualidade esta que de algum modo pertence à categoria dos talentos naturais), mas sempre melhora o conteúdo desta didática, a sua substância, a essência de sua mensagem. A pesquisa coloca o saber de quem ensina num contexto mais amplo, mais rico, define seu contorno, unifica, acrescenta nuanças, lhe dá versatilidade, relevo, vida, alegria... (TSALLIS, 1985, p. 570)
\end{abstract}

Aliando a pesquisa ao Ensino de Física, pode-se promover mudanças necessárias para que o processo de ensino da referida disciplina esteja voltado para a realidade do aluno, promovendo uma aprendizagem mais significativa, onde o aluno seja capaz de atuar na construção do próprio conhecimento, utilizando dos recursos disponíveis no meio onde está inserido.

\title{
4. MATERIAIS E MÉTODOS
}

Para organizar a coleta de dados e desenvolvimento da pesquisa, inicialmente foi necessário realizar um levantamento sobre os projetos de pesquisa da Universidade Federal da Fronteira Sul vinculados ao curso LEDOC-CNMA. Por meio da pesquisa 
documental no portal UFFS (https://www.uffs.edu.br/), foram encontrados registros destes projetos desde o ano de 2013 até novembro de 2017, os quais são listados na tabela 1, onde consta o detalhamento de cada um. Como pode-se observar na tabela, dois dos projetos desenvolvidos, que estão registrados em quatro editais diferentes, são voltados para a área de Física, enfatizando o ensino da disciplina através de experimentos didáticos de baixo custo.

Foi avaliada a opinião de alguns estudantes do Curso LEDOC-CNMA acerca da relação entre os projetos de pesquisa universitária com o progresso dos mesmos nas disciplinas de Física, por meio de uma pesquisa qualitativa de cunho exploratório (BOGDAN; BIKLEN, 1994). Para tanto, foram selecionados os estudantes que participaram dos projetos de pesquisa relacionados à Física vinculados ao curso (tabela 1), e estes foram convidados a participar de uma entrevista estruturada, através da aplicação de um questionário composto por questões discursivas. As questões foram formuladas no aplicativo Google Formulários e analisadas no Planilhas Google.

No total foram 16 participantes, sendo que dois eram bolsistas, um já havia finalizado seu contrato de bolsa e 13 estavam participando ou haviam participado como voluntários. Além disso, dos 16 participantes, 8 já haviam se formado na época da entrevista (novembro de 2017) e 8 ainda estavam participando dos projetos. Destaca-se ainda que o autor deste trabalho participou de um dos projetos mencionados (como bolsista), mas não contribuiu com sua opinião como participante, devido ao fato de ser o entrevistador nesta pesquisa.

Tabela 1 - Lista de projetos de pesquisa do curso Interdisciplinar em Educação do Campo: Ciências Naturais, Matemática e Ciências Agrárias.

\begin{tabular}{|c|c|c|c|}
\hline Título do projeto & Edital $\mathbf{n}^{\mathbf{0}}$ & $\begin{array}{l}\text { Área do conhecimento } \\
(\text { (CNPq) }\end{array}$ & $\begin{array}{c}\text { Vigência } \\
\text { (início e término) }\end{array}$ \\
\hline $\begin{array}{c}\text { Fatores } \\
\text { socioeconômicos que } \\
\text { influenciam o aluno na } \\
\text { escolha profissional } \\
\text { após conclusão do } \\
\text { Ensino Médio }\end{array}$ & $218 / 2013$ & Educação & $08 / 2013$ a $07 / 2014$ \\
\hline $\begin{array}{l}\text { Direitos Humanos } \\
\text { Interculturais }\end{array}$ & $281 / 2015$ & Ciências Humanas & 08/2015 a 07/2016 \\
\hline O Ensino de Física & $281 / 2015$ & Ensino/Aprendizagem & 08/2015 a 07/2016 \\
\hline
\end{tabular}


através de experimentos

didáticos de baixo custo

A Educação do campo e

o plano municipal de educação: da

281/2015 Ciências Humanas

08/2015 a 07/2016

epistemologia à prática

O Ensino de Física através de experimentos didáticos de baixo custo

385/2016 Ensino/Aprendizagem

$08 / 2016$ a $07 / 2017$

Ensino de Física no

Ensino Médio: uso de experimentos de baixo custo

O Ensino de Física através de experimentos didáticos de baixo custo

593/2016 Ciências Humanas 01/2017 a 12/2017

398/2017 Ciências Humanas 08/2017 a 07/2018

Fonte: Disponível em https://www.uffs.edu.br/. Acessado em 16/11/2017.

A entrevista estruturada era composta por 11 questões abertas, destinadas aos 16 acadêmicos e ex-acadêmicos do curso mencionados anteriormente. Os questionários foram enviados por e-mail, o que ofereceu uma maior flexibilidade de acesso, visto que muitos destes estudantes possuíam atividades profissionais e horários não compatíveis com o período de aula para que as entrevistas fossem realizadas pessoalmente. Adicionalmente, as respostas recebidas via e-mail também ofereceram maior facilidade na organização dos dados.

As referidas questões, além de terem o objetivo de levantar dados sobre a influência da participação dos estudantes em projetos de pesquisa no desempenho em Física, visavam verificar a contribuição desta participação na formação docente dos sujeitos. As respostas dadas foram reproduzidas fidedignamente e a identidade dos entrevistados preservada, sendo atribuídos números aos participantes (por exemplo: Entrevistado 1, Entrevistado 2,...).

\section{RESULTADOS E DISCUSSÃO}

Como comentado na seção anterior, foi realizada uma entrevista estruturada em 11 questões aplicada a 16 entrevistados do curso LEDOC-CNMA da UFFS. A primeira questão da entrevista buscou saber o motivo que levou o aluno a participar dos projetos de pesquisa. As respostas obtidas apontaram três motivos principais, sendo a 
necessidade de horas complementares, a consciência sobre a importância de maior conhecimento a respeito de novas metodologias de ensino em Física, visando a formação profissional, e a dificuldade pessoal na compreensão dos conteúdos relacionados à Física.
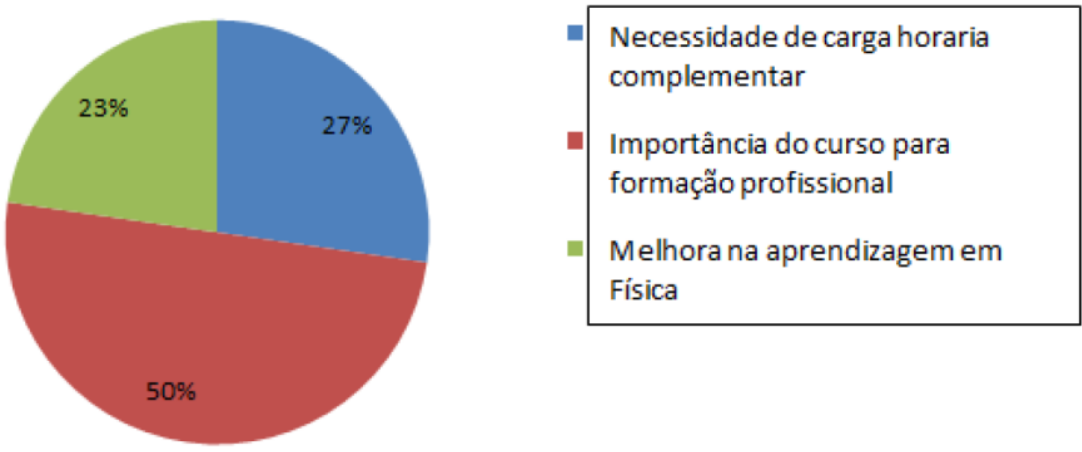

Figura 1 - Motivo que levou o entrevistado à participação no projeto.

Na figura 1 estão apresentados os resultados da questão sobre os motivos que levaram a participar de projetos, no qual $100 \%$ corresponde ao total de 16 respostas. Observa-se que 11 participantes relacionaram a importância dos projetos com a obtenção de conhecimento de outras metodologias de ensino por meio de atividades práticas (a partir da realização de experimentos didáticos de baixo custo), visando melhor formação profissional; 6 estudantes participaram dos projetos para angariar horas complementares para a formação acadêmica (cuja exigência era de 210 horas) e 5 afirmaram ter participado dos projetos para facilitar a própria aprendizagem em Física. Cabe ressaltar que alguns estudantes participaram dos projetos por mais de um motivo, o que altera a soma de participantes ao observar apenas o gráfico demonstrativo.

Foi questionado em que fase (período) da graduação o estudante começou a participar de algum projeto e de qual projeto participou. As respostas obtidas relacionadas ao período de entrada em um dos projetos estão demonstradas na figura 2. 


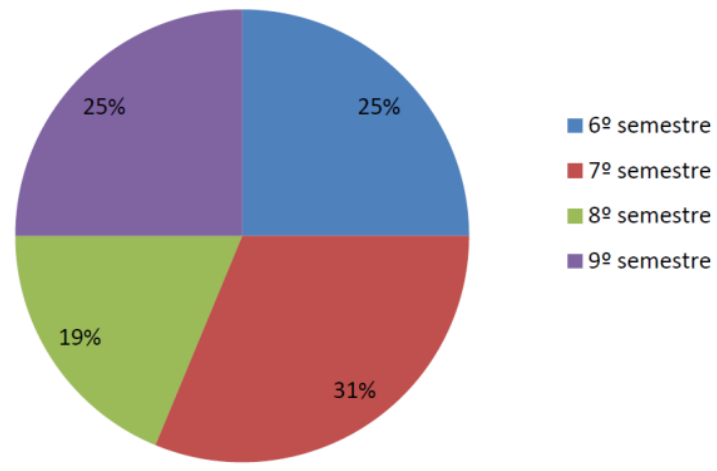

Figura 2 - Fase da graduação em que o entrevistado participou de projeto de pesquisa em Física.

$\mathrm{O}$ projeto de pesquisa que mais teve participantes foi o "O Ensino de Física através de experimentos didáticos de baixo custo", com 10 dos entrevistados participantes, sendo que os outros 6 participaram do projeto "Ensino de Física no Ensino Médio: uso de experimentos de baixo custo", como mostra a figura 3.

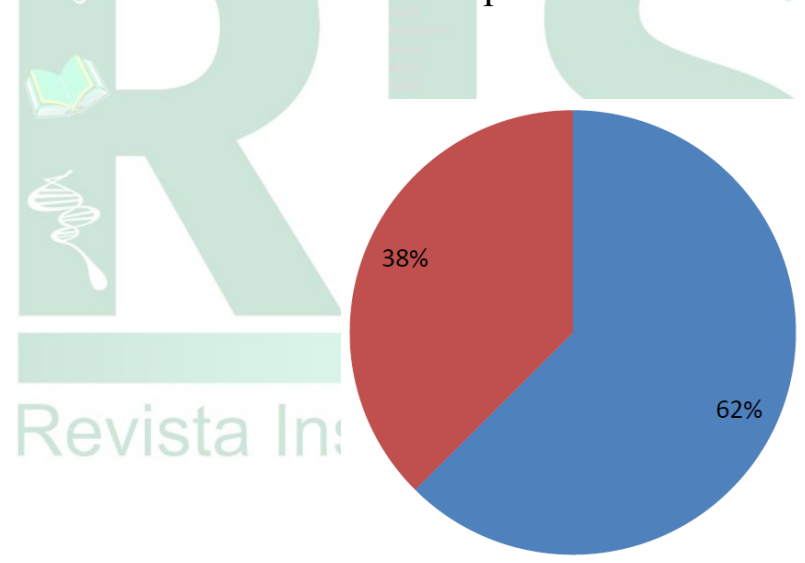

- Ensino de Física através de experimentos didáticos de baixo custo

- Ensino de Física no Ensino Médio: uso de experimentos de baixo custo

Figura 3 - Projeto de pesquisa em Física do qual o entrevistado participou.

De acordo com os relatos, os projetos consistiram em desenvolvimento de experimentos para descreverem fenômenos físicos com a utilização de materiais de baixo custo, inclusive sucatas. Além disso, foram realizadas oficinas em/para escolas públicas e exposições em feiras de conhecimento promovidas pelas escolas/UFFS, onde estes fenômenos eram explicados aos estudantes, permitindo aos pesquisadores maior aproximação com a prática docente, por meio do desenvolvimento de metodologias de ensino variadas.

Os licenciandos foram inquiridos em relação ao tempo de permanência nos projetos de pesquisa em Física, que variou de acordo com o aluno e sua disponibilidade de participação. Desta forma, embora os planos de trabalho dos participantes dos 
projetos sejam elaborados contemplando, no mínimo, 6 meses, a participação dos entrevistados variou entre três meses a um ano, conforme mostra a figura 4 .

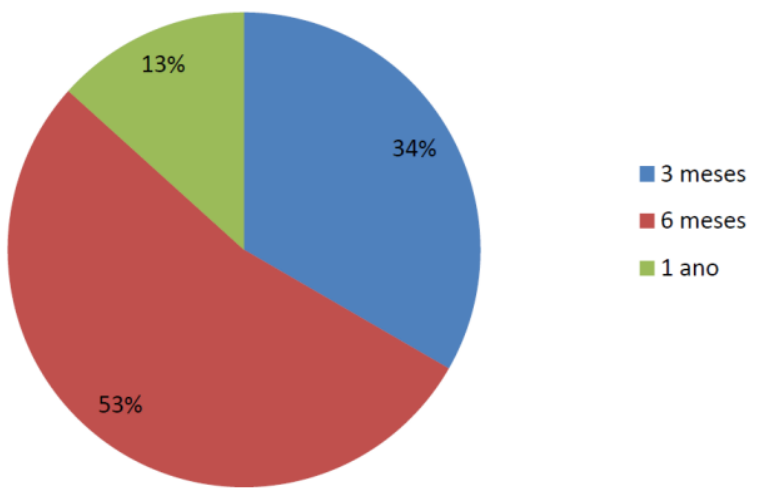

Figura 4 - Tempo de participação do entrevistado em projeto de pesquisa em Física.

Foi indagado o desempenho dos estudantes na disciplina de Física durante a graduação no curso LEDOC-CNMA, questionando se o aluno já havia tido reprovação em alguma disciplina de Física durante seu percurso acadêmico, até a participação em projeto. O resultado foi que 8 dos 16 entrevistados já haviam reprovado em algum dos componentes curriculares obrigatórios do curso que estão descritos na figura 5.

Percebe-se um número maior de reprovações em Física na Educação Básica I e II, sendo que, no caso da Física na Educação Básica III, nem todos os estudantes entrevistados já haviam concluído esta disciplina. Ressalta-se, ainda, que os números se alteram em relação à quantidade de participantes, pelo fato de que um mesmo estudante pode ter reprovado mais de uma vez em cada fase. Por exemplo, um dos estudantes reprovou 4 vezes em Física na Educação Básica I e outras duas vezes em Física na Educação Básica II. Para melhor entendimento, os dados estão dispostos na tabela 2.
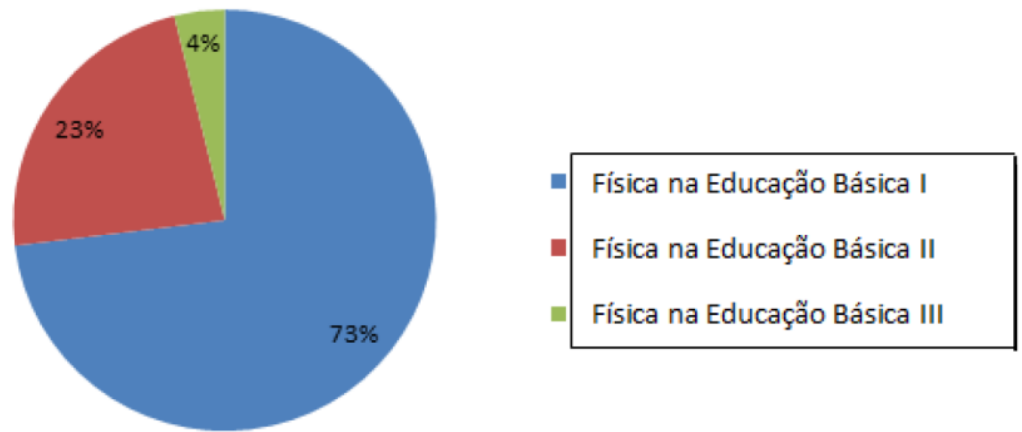

Figura 5 - Índice percentual de reprovação por disciplina antes da participação do entrevistado em projeto de pesquisa em Física. 
Tabela 2 - Ocorrências de reprovação em Física antes da participação do entrevistado em projetos de pesquisa.

$\begin{array}{ccc}\text { FÍSICA NA } & \text { FÍSICA NA } & \text { FÍSICA NA } \\ \text { EDUCAÇÃO } & \text { EDUCAÇÃO } & \text { EDUCAÇÃO BÁSICA } \\ \text { BÁSICA I } & \text { BÁSICA II } & \text { III }\end{array}$

\begin{tabular}{|c|c|c|c|}
\hline Entrevistado 1 & 2 reprovações & 0 reprovação & $\begin{array}{l}\text { Ainda não havia } \\
\text { concluído }\end{array}$ \\
\hline Entrevistado 2 & 1 reprovação & 2 reprovações & 1 reprovação \\
\hline Entrevistado 3 & 1 reprovação & 0 reprovação & $\begin{array}{l}\text { Ainda não havia } \\
\text { concluído }\end{array}$ \\
\hline Entrevistado 4 & 0 reprovação & 1 reprovação & 0 reprovação \\
\hline Entrevistado 5 & 1 reprovação & 0 reprovação & 0 reprovação \\
\hline Entrevistado 6 & 2 reprovações & 0 reprovação & 0 reprovação \\
\hline Entrevistado 7 & 2 reprovações & 0 reprovação & $\begin{array}{l}\text { Ainda não havia } \\
\text { concluído }\end{array}$ \\
\hline Entrevistado 8 & 4 reprovações & 1 reprovação & 0 reprovação \\
\hline Entrevistado 9 & 0 reprovação & 0 reprovação & 0 reprovação \\
\hline Entrevistado 10 & 4 reprovações & 0 reprovação & $\begin{array}{l}\text { Ainda não havia } \\
\text { concluído }\end{array}$ \\
\hline Entrevistado 11 & 0 reprovação & 0 reprovação & 0 reprovação \\
\hline Entrevistado 12 & 1 reprovação & 1 reprovação & 0 reprovação \\
\hline Entrevistado 13 & 0 reprovação & 1 reprovação & 0 reprovação \\
\hline Entrevistado 14 & 1 reprovação & 0 reprovação & 0 reprovação \\
\hline Entrevistado 15 & 0 reprovação & 0 reprovação & 0 reprovação \\
\hline Entrevistado 16 & 0 reprovação & 0 reprovação & 0 reprovação \\
\hline $\begin{array}{l}\text { TOTAL } \\
\end{array}$ & 19 reprovações & 6 reprovações & 1 reprovação \\
\hline
\end{tabular}

Os resultados sugerem uma grande dificuldade de compreensão da Física pelos estudantes, sendo que alguns citam que têm essas dificuldades desde o Ensino Médio. É possível que essas dificuldades resultem de um Ensino de Física sem relação com a realidade, conforme já citado o que discutem Pedrisa (2001) e Diogo e Gobara (2007) sobre os problemas relacionados ao Ensino de Física no Brasil, que vêm desde o Ensino Médio, citando o método expositivo, a dependência excessiva de livros didáticos, a ausência da prática experimental, o currículo desatualizado e descontextualizado, somando-se a carga horária carregada do professor.

Com o objetivo de averiguar o impacto da participação dos entrevistados nos projetos de pesquisa, foi perguntado se após a participação algum estudante reprovou em Física. Para tal questão, entre os 8 que afirmaram já terem reprovado (e concluído todas), as respostas foram unânimes em não terem tido mais nenhuma reprovação em Física. Os que nunca haviam reprovado não precisavam responder a questão. 
Uma questão complementar buscou saber dos estudantes se a disciplina de Física ficou mais compreensível a partir de sua participação no projeto. Todos afirmaram que sim, sendo que a resposta dada pelo Estudante 3 resume bem o que foi afirmado:

"Sim, a partir do projeto a Física tornou-se mais compreensível, pois através dos experimentos era possível visualizar os fenômenos físicos na prática, deixando o ensino mais dinâmico e atrativo" (Entrevistado 3).

Os resultados obtidos nas duas últimas questões apresentadas anteriormente indicam um avanço na aprendizagem e compreensão dos conteúdos de Física a partir da participação nos projetos de pesquisa. Considerando que estes projetos tinham como objetivo o desenvolvimento de experimentos de fenômenos físicos, percebe-se que, não apenas para a formação do estudante para futuro exercício docente, o projeto contribuiu para superação das dificuldades de aprendizagem em Física reveladas por alguns dos entrevistados. Pesquisas em experimentação em Ciências mostram a possibilidade de este tipo de metodologia estimular a participação do sujeito, explorando sua curiosidade e fazendo o estudante exercer o papel principal no processo da construção de conhecimentos (GONÇALVES; SILVA; VILARDI, 2020). Neste sentido, pode-se afirmar que houve um movimento de aprendizagem significativa por meio destas atividades experimentais:

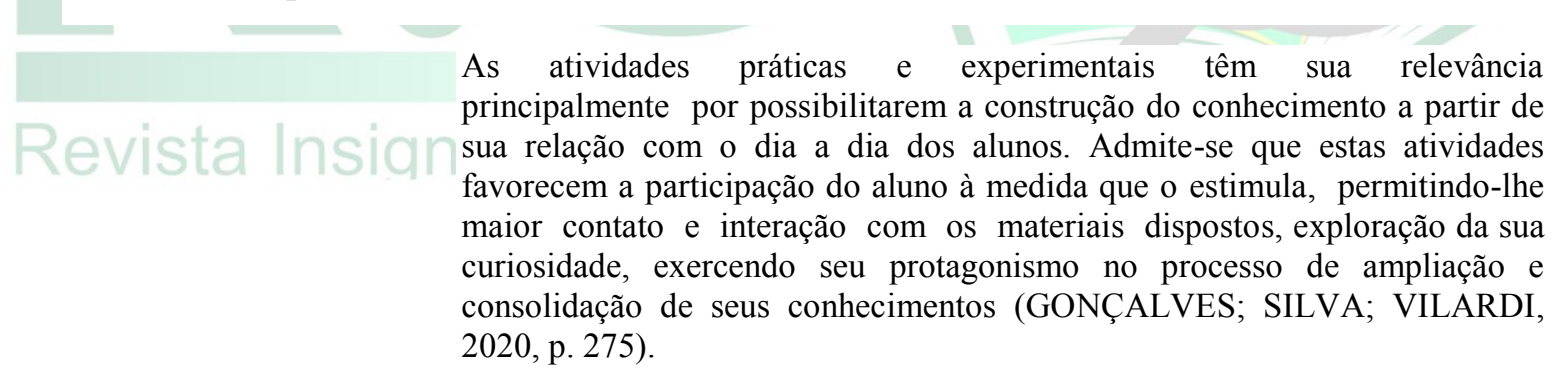

A entrevista da presente pesquisa também buscou saber se, na opinião do entrevistado, a participação no projeto contribuiu ou contribuirá para a sua formação docente. Todos responderam positivamente, dentre as respostas, as registradas a seguir demonstram essa posição:

"Sim, os experimentos desenvolvidos no projeto possibilitam a compreensão do fenômeno físico, pois em sala de aula, a Física costuma resumir-se em cálculos" (Entrevistado 2).

"Certamente, além das pesquisas que ampliam nosso conhecimento, ministrar oficinas para escolas, com uma linguagem acessível aos estudantes nos prepara para a formação" (Entrevistado 5).

"Sem dúvida alguma o projeto contribuiu para minha formação enquanto docente, afinal, através do projeto houve uma maior aproximação com o ensino de Física, contribuindo para uma maior relação entre a teoria e a 
prática, o que contribui para uma melhora do ensino-aprendizagem dos estudantes durante as aulas de Física" (Entrevistado 6).

"O projeto proporcionou demonstrar fenômenos físicos com materiais que iriam até para o lixo muitas vezes, Isso prova que é possível fazer aulas experimentais mesmo em uma escola que não possua laboratório de Física" (Entrevistado 9).

Tendo em mente a formação do acadêmico, foi feita uma questão relacionada à produção do Tabalho de Conclusão de Curso (TCC) da graduação em LEDOC-CNMA na área de Física, averiguando se o estudante era estimulado pela participação nos projetos de pesquisa. Dos 16 participantes, 8 afirmaram que sim, o projeto os estimulou a desenvolver seu TCC em Física, três afirmaram ainda não ter decidido sobre o tema do TCC, dois já haviam concluído o TCC em outra área quando iniciaram sua participação nos projetos e outros três já haviam desenvolvido o TCC em outra área de formação.

Foi solicitado aos entrevistados que indicassem os pontos positivos e negativos da sua participação nos projetos de Física. Analisando os dados levantados, pode-se elencar vários pontos positivos. Para melhor compreensão, listamos as respostas na tabela 3 .

Tabela 3 - Indicação pelos entrevistados de pontos positivos e negativos relacionados à participação em projetos de pesquisa.

\begin{tabular}{c}
\hline Pontos positivos \\
\hline Entrevistado 1 "Melhor posicionamento e melhor fala em público e um melhor \\
entendimento de conteúdo da física."
\end{tabular}

"Tudo o que minha participação no referido projeto trouxe, isso certamente Entrevistado 2 irá contribuir com meu TCC, porque vou ter segurança para escrever e falar sobre o tema, justamente por estar mais familiarizada com o que é a física."

Entrevistado 3

Entrevistado 4

Entrevistado 5

Entrevistado 6
"Maior relação entre teoria e prática, a maior interação e aproximação dos conteúdos físicos com o cotidiano dos estudantes, a possibilidade de construção de experimentos físicos com materiais de baixo custo."

"Acredito que só tenha apreciado pontos positivos ao projeto, como conceitos físicos vistos no projeto e não no curso."

"Para mim, o projeto teve somente pontos positivos, vi que um experimento precisa de muitos testes, nem sempre dá certo. Aprendi a fazer roteiro.

Aproximou-me de estudantes através das feiras e visitas que as escolas fazem para verem os experimentos. O projeto aproxima-nos da carreira docente."

“Ajudei no desenvolvimento de vários experimentos que facilitam no aprendizado de física e também pude participar de feira de ciências para demonstrar alguns experimentos construídos."

Entrevistado $7 \quad$ "Tudo que aprendi nesse curto período em que participei foi muito

\section{Pontos} negativos

"A maior necessidade de disponibilidade de tempo para o projeto."

Não citou.

Não citou.

Não citou.

Não citou.

Não citou.

Não citou. 
gratificante e muito produtivo, creio que o projeto em si já é um grande ponto positivo."

Entrevistado 8

“Compreensão da física, pois na teoria muitas vezes não conseguimos absorver a realidade da Física."

Não citou.

"Através do projeto é possível ter um melhor entendimento de física, através

Entrevistado 9 dele é possível pensar em uma metodologia diferenciada para as aulas de física no estágio."

Não citou.

"Os pontos positivos foram a convivência no grupo e o aprendizado sobre a

Entrevistado 10 física em si e pessoalmente não posso citar nenhum ponto negativo porque não os observei enquanto fiz parte do grupo."

"-Ajudou a assimilar os conteúdos.

Entrevistado 11 -Ganhei experiência ao escrevermos artigo. -Aprendi a escrever roteiros.

Não citou -Os experimentos sempre ajudaram a adquirir conhecimentos."

"Para mim, o projeto teve somente pontos positivos, vi que um experimento precisa de muitos testes, nem sempre dá certo. Aprendi a fazer roteiro.

Entrevistado 12 Aproximou-me de estudantes através das feiras e visitas que as escolas fazem para verem os experimentos. O projeto aproxima-nos da carreira docente."

Entrevistado 13

Entrevistado 14

"Participação e realização de experimentos e em feiras"

"Destaco o trabalho em equipe, o estimulo a pesquisa, aprendizado importante de como preparar atividades sem gastar muito."

Não citou.

Não citou.

Não citou.

Não citou.

"Desenvolvimento de alternativas para escolas sem laboratórios e materiais.

Entrevistado 15

Revisão de conteúdo.

Elaboração de relatório."

Entrevistado 16

"Relação da teoria e a prática através de experimentos"

Não citou.

Não citou.

Os licenciandos foram questionados sobre a influência dos projetos na carreira docente. Dos 16 entrevistados, todos consideraram que a participação nos projetos seria de grande valia para a carreira docente. Dentre as afirmações, são citadas as atividades experimentais desenvolvidas durante o projeto, sendo mais relevante a questão do baixo custo na realização dos experimentos.

Diante da realidade vivenciada nas escolas, principalmente da rede pública de ensino, sabe-se da carência de recursos e da precariedade do espaço físico disponível. Pensar numa escola que possui um laboratório bem equipado, com todos os recursos disponíveis para realização de experimentos físicos, é saber que são raras exceções. Desta forma, considera-se a possibilidade da realização de experimentos com materiais de baixo custo e de fácil aceso como uma contribuição ímpar na formação dos docentes, pois significa a possibilidade de aulas mais atrativas, significativas, onde os estudantes podem relacionar a teoria e a prática. Além do mais, podem fazer suas descobertas, enriquecer seu conhecimento por meio das novas metodologias de ensino aprendidas pelo professor, através da participação em projetos de pesquisa, em sua formação acadêmica (VALADARES, 2001). 
Por fim, a última questão buscou saber, nos casos em que o entrevistado já graduado estava ministrando aula, se, a partir do projeto, se sentia mais motivado para aplicar diferentes metodologias em sala de aula. As respostas obtidas vêm de encontro ao que foi citado em relação aos pontos positivos do projeto:

\begin{abstract}
"Com certeza. As aulas devem ser motivadoras, penso que o professor deve sempre estar elaborando suas aulas no sentido de fazer com que o aluno sinta vontade de interagir, perguntar, argumentar, ou seja, deve fazer a diferença. Sendo assim, o professor acaba ficando mais próximo do aluno e as aulas se tornam mais agradáveis e de melhor compreensão" (Entrevistado 6).

“As aulas que ministrei até o momento foram as do estágio. E sim, com o projeto é possível pensar em uma metodologia que vai além de calculo" (Entrevistado 2).

"Sim, com o projeto vi possibilidades de realizar aulas experimentais sem ter um laboratório disponível” (Entrevistado 5).

"Sim, nos dá mais confiança em sala de aula e contribui de forma positiva para que possamos realizar aulas mais atrativas para os alunos de forma que as aulas se tornem mais significativas" (Entrevistado 1).
\end{abstract}

\title{
6.CONSIDERAÇÕES FINAIS
}

A proposta deste trabalho foi analisar os impactos dos projetos de pesquisa na aprendizagem de Física dos estudantes do curso de Licenciatura Interdisciplinar em Educação do Campo: Ciências Naturais, Matemática e Ciências Agrárias da UFFS Laranjerias do Sul, buscando saber se estes projetos contribuem de forma positiva para o desenvolvimento da aprendizagem em Física dos acadêmicos e também para a sua formação profissional.

Na linha de pesquisa universitária em Física, se faz necessária a superação de um modelo de ensino desta disciplina voltado a aulas expositivas e livrescas, sendo esta uma das que mais os estudantes apresentam dificuldades de aprendizagem. Diante disso, é preciso um investimento maior na formação de professores para possibilitar um ensino que promova um aprendizado mais significativo, relacionando as teorias à prática, por meio de atividades experimentais e, assim, promovendo a interdisciplinaridade. Para tanto, os projetos oferecidos no curso LEDOC-CNMA buscaram oferecer experiências didáticas diferenciadas, objetivando essa formação, principalmente para atuação em escolas do campo. A oferta de projetos de pesquisa pela UFFS como os citados neste trabalho, bem como o curso de Educação do Campo, vem buscando modificar a realidade das escolas do campo, cujas metodologias e conteúdos seguem uma linha geral, com um modelo urbano, que não valoriza as especificidades da vida e dessas 
escolas, que apresentam inúmeras deficiências, que vão desde a estrutura física até a falta de profissionais devidamente formados para atuarem nessa modalidade de ensino tão peculiar.

Pode-se perceber que muitos dos entrevistados apresentavam dificuldades de aprendizagem em Física e, com a participação nos projetos de pesquisa, superaram essas dificuldades, atribuindo isso à realização de atividades experimentais, participação em oficinas e exposições científicas. Além disso, de acordo com as respostas dadas pelos entrevistados, há um reconhecimento sobre a contribuição dos projetos na adoção de novas metodologias e estratégias didáticas para o ensino da Física, o que demonstra uma identificação deles com a proposta do curso que é formar docentes qualificados e comprometidos com a Educação. Percebe-se que a formação adequada promove um ensino de qualidade, pois sabe-se da importância da relação entre a teoria e a prática para promoção da construção de um conhecimento sistematizado e significativo.

Espera-se que, a partir de um diagnóstico sobre os problemas existentes nas aulas da disciplina de Física citados ao longo deste trabalho, possa ser repensada a forma de se ensinar Física, pois foram claramente observadas as contribuições de uma metodologia de ensino por meio de experimentos envolvendo os fenômenos físicos para uma melhor aprendizagem dos acadêmicos. Ademais, espera-se que cada vez mais projetos de pesquisa em Ensino possam contribuir para uma formação acadêmica mais rica, visando a formação de profissionais competentes para mudar a realidade do ensino no Brasil, principalmente no que se refere à Educação do Campo.

\section{REFERÊNCIAS}

ANDRADE, M. M. de. Introdução à metodologia do trabalho científico: elaboração de trabalhos na graduação. 6. Ed. São Paulo: Atlas, 2003.

ARAÚJO, F. R. de S.; SALGUES, L. J. de V. A problemática da interdisciplinaridade nos cursos de graduação em administração: proposta para reflexão teórica. In: Seminários em Administração FEA-USP, 2005, São Paulo - SP. Anais do VIII SEMEAD, 2005.

BOGDAN, R. C.; BIKLEN, S. K. Investigação qualitativa em educação: uma introdução à teoria e aos métodos. Lisboa: Porto Editora, 1994.

BRASIL. Constituição (1988). Constituição da República Federativa do Brasil. 
Brasília, DF: Senado Federal: Centro Gráfico, 1988. 292 p.

BRASIL. Estatuto da Universidade Brasileira. Decreto ${ }^{\circ} 19.851$ de 11 de abril de 1931.

BRASIL. Base Nacional Comum Curricular (BNCC). Educação é a Base. Brasília: MEC/CONSED/UNDIME, 2017.

DEMO, P. O profissional do futuro. In: LINSIGEN, I. V. (Org.). Formação do engenheiro: desafios da atuação docente, tendências curriculares; questões contemporâneas da educação tecnológica. Florianópolis: UFSC, 1999.

DIOGO, R. C.; GOBARA, S. T. Sociedade, educação e ensino de física no Brasil: do Brasil Colônia ao fim da Era Vargas. In: Simpósio Nacional de Ensino de Física, 17, 2007, São Luis. Anais [...]. São Luis: Sociedade Brasileira de Física, 2007.

GONÇALVES, F. H. C.; SILVA, A. C. R.; VILARDI, L. G. A. Os desafios da utilização do laboratório de ensino de Ciências pelos professores de Ciências da Natureza. Revista Insignare Scientia, v. 3, n. 2, p. 274-291, 2020.

NARDI, R. Memórias da Educação em Ciências no Brasil: A pesquisa em Ensino de Física. Investigações em Ensino de Ciências, v.10(1), p. 63-101, 2005.

PEDRISA, C. M. Características históricas do ensino de ciências. Ciência \& Ensino, Campinas, n. 11, p. 9-12, 2001.

SCHWARTZMAN, S.; CASTRO, C. de M. A pesquisa científica no Brasil: Matrizes culturais e institucionais. In: GONÇALVES, E. de L. Pesquisa Médica. São Paulo: Editora Pedagógica Universitária; Brasília: Conselho Nacional de Desenvolvimento Científico e Tecnológico, 1982. p.137-160.

SILVA. R. S. Panorama da pesquisa universitária no Brasil: angústias e proposições. Olhares \& Trilhas, v. 16, n. 2, 2014.

SOUZA, C. C. de. A importância dos projetos de extensão universitária na formação de professores: o caso do curso de licenciatura Interdisciplinar em Educação no Campo. Trabalho de Conclusão de Curso (Graduação em Licenciatura Interdisciplinar em Educação do Campo: Ciências Naturais, Matemática e Ciências Agrárias) - Universidade Federal da Fronteira Sul, Laranjeiras do Sul - PR, 2017.

TREVISOL, J. V.; CORDEIRO, M. H.; HASS, M. Construindo agendas e definindo rumos. I conferência de ensino, pesquisa e extensão da UFFS/Universidade Federal da Fronteira Sul (COEPE), 2011. Chapecó: UFFS, 2011. p. 280.

TSALLIS, C. Por que pesquisa na Universidade? Ciência e Cultura, v. 37, n. 4, p.570$572,1985$.

UFFS. Universidade Federal da Fronteira Sul. Política de extensão da UFFS. PróReitoria de Extensão e Cultura - PROEC. Chapecó, 2011. 21 p. 
UFFS. Universidade Federal da Fronteira Sul. Projeto Pedagógico do Curso de Interdisciplinar em Educação no Campo. Laranjeiras do Sul, 2014, 316 f.

VALADARES, E. C. Novas Estratégias de Divulgação Científica e de Revitalização do Ensino de Ciências nas Escolas. Física na Escola, v. 2, n. 2, p. 10-13, 2001.

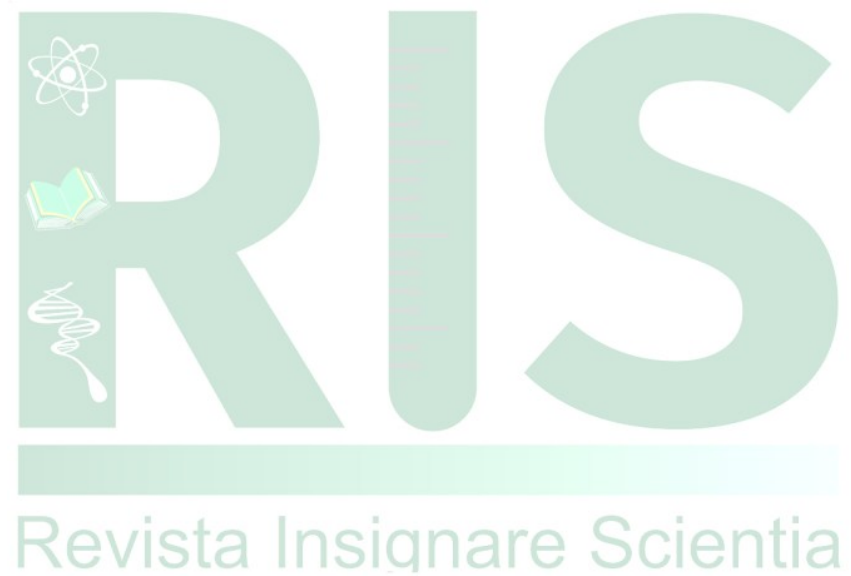

